\title{
Eksplorasi Strategi Guru untuk Meningkatkan Keterlibatan Siswa dalam Aktifitas Membaca
}

\section{Exploring Teacher's Strategies to Encourage Student Engagement in Reading Activity}

\author{
Siti Nurul Hidayati*, dan Rojab Siti Rodliyah \\ Universitas Pendidikan Indonesia, Bandung, Jawa Barat, Indonesia \\ sitinurulhidayati33@gmail.com*,rojab@upi.edu
}

Naskah diterima tanggal 17/11/2019, direvisi akhir tanggal 12/02/2020, disetujui tanggal 24/04/2020

\begin{abstract}
Abstrak
Penelitian ini bertujuan untuk mengeksplorasi bagaimana meningkatkan keterlibatan siswa dalam membaca dengan mengidentifikasi dan memahami strategi guru bahasa Inggris yang unggul dalam membina siswa dalam belajar membaca. Data tentang guru diperoleh dari wawancara dengan kepala sekolah dan guru. Selain itu, guru dipilih berdasarkan pengalaman mengajar, prestasi di tingkat nasional dan tulisannya tentang strategi membaca. Data dikumpulkan melalui wawancara semi-terstruktur dan analisis dokumen dalam bentuk rencana pelaksanaan pembelajaran. Data dianalisis berdasarkan kerangka dari Guthrie dan Cox (2001) karena dapat mengakomodasi ketiga elemen dalam penelitian ini; strategi guru, keterlibatan, dan membaca. Hasil penelitian ini mengungkapkan bahwa guru telah berhasil melakukan strategi yang menarik seperti kegiatan langsung, lingkaran sastra, pengajaran kuantum, pembelajaran kolaboratif, dan bimbingan teman sebaya, seperti yang disarankan di masingmasing fase kerangka keterlibatan membaca.
\end{abstract}

Kata kunci: Bimbingan teman sebaya, kegiatan langsung, keterlibatan siswa, lingkaran sastra, pengajaran kuantum.

\begin{abstract}
The present study aims to explore how to engage the students in reading by identifying and understanding the strategies of English teacher who excels at fostering student learning in reading. Data on the excellent teacher were obtained from interviews with the school leader and teachers. Additionally, the excellent teacher was selected based on her teaching achievement at the national level and her published book on reading strategies. Data were collected through a semi-structured interview and document analysis in the form of a lesson plan. The data were analyzed based on the framework from Guthrie and Cox (2001) since it accommodates all three elements in this study; teacher strategies, engagement, and reading. The results revealed that the teacher has managed to perform engaging strategies such as hands-on activities, literature circle, quantum teaching, collaborative learning, and peer tutoring, as suggested in each phase of the framework of reading engagement.
\end{abstract}

Keywords: Hands-on activities, literature circle, peer tutoring, student engagement, quantum teaching.

\section{PENDAHULUAN}

Karena membaca adalah salah satu keterampilan reseptif yang pada akhirnya akan mempengaruhi keterampilan bahasa lainnya, meningkatkan keterlibatan siswa di dalam bidang ini sangat penting. Sehubungan dengan hal ini, sebuah pertanyaan kemudian muncul tentang bagaimana cara memicu 
motivasi siswa untuk lebih terlibat dalam aktifitas membaca. Pertama-tama, keterlibatan dalam konteks pendidikan mengacu pada sejauh mana partisipasi aktif siswa dalam kegiatan akademik yang dapat ditunjukkan dengan upaya, kegigihan, dan tindakan (Skinner et al., 1990; Skinner \& Belmont, 1993). Sementara itu, khusus untuk pelajaran bahasa, keterlibatan menyangkut tingkat keterlibatan siswa dan partisipasi mereka dalam kegiatan atau tugas khusus di dalam kelas untuk tujuan pembelajaran (Philp \& Duchesne, 2016). Kegiatan di kelas tergantung pada keterampilan yang diajarkan pada saat mengajar. Dalam banyak kasus, keterampilan bahasa Inggris dasar diajarkan secara bersamaan atau secara integratif. Dengan demikian, penelitian ini berfokus pada keterlibatan siswa di kegiatan membaca yang umumnya terintegrasi dengan keterampilan lain seperti menulis dan berbicara.

Dalamkegiatanmembaca, keterlibatan didefinisikan sebagai titik temu pengoperasian strategi kognitif dan motivasi (Guthrie \& Wigfield, 2000). Berdasarkan definisi di atas, keterlibatan melibatkan perilaku, emosi, dan motivasi seseorang dalam membaca. Dengan kata lain, keterlibatan dalam membaca dikonseptualisasikan sebagai multidimensi (Fredricks et al., 2004). Multidimensi berarti keterlibatan dibagi menjadi keterlibatan perilaku (behavioral), emosi (emotional), dan kognitif (cognitive).

Keterlibatan perilaku mengacu pada gagasan partisipasi aktif. Contoh khusus dari keterlibatan perilaku adalah menghadiri kelas, berpartisipasi secara sukarela di ruang kelas, dan terlibat dalam kegiatan ekstrakurikuler. Keterlibatan perilaku bisa dilihat saat siswa mengangkat tangan, merespons guru, dan menunjukkan perhatian pada guru atau tugas (Downer et al., 2007). Keterlibatan emosi, di sisi lain, didefinisikan sebagai reaksi afektif siswa di kelas saat berinteraksi dengan guru, teman sebaya, tugas sekolah, dan sekolah. Keterlibatan emosi dapat diamati dalam bentuk kehadiran, rasa ingin tahu, minat, antusiasme, dan tidak adanya ketakutan, kegelisahan, dan rasa frustrasi (Mahatmya et al., 2012). Sementara itu, keterlibatan kognitif didefinisikan sebagai investasi internal dalam pekerjaan pembelajaran yang menggabungkan komitmen dalam membuat upaya untuk menguasai keterampilan yang sulit dan mencapai lebih dari pemahaman minimum (Fredricks et al., 2004; Mahatmya et al., 2012). Keterlibatan kognitif melibatkan seseorang untuk menggunakan pembelajaran strategi, mencari pemahaman konseptual, dan menggunakan pengaturan sendiri strategi. Tidak seperti keterlibatan perilaku, keterlibatan kognitif tidak dapat dinilai secara langsung. Ketiga aspek keterlibatan ini dianggap saling terkait. Jika seorang siswa menggabungkan motivasinya dengan strategi kognitif yang ditunjukkan melalui perilaku mereka, keterlibatan membaca nereka diklaim berpengaruh secara positif.

Namun demikian, keterlibatan siswa bukanlah sebuah proses instan. Untuk dianggap memiliki keterlibatan tinggi dalam membaca, siswa harus memiliki strategi, termotivasi, berpengetahuan luas, dan interaktif secara sosial dalam aktifitas membaca (Baker et al., 1996). Akibatnya, pembaca yang terlibat tidak hanya membaca apa adanya, tetapi mereka menerapkan strategi dalam agar bacaan lebih mudah dipahami, memiliki motivasi dalam melakukan tugas mereka dalam membaca, mengaktifkan pengetahuan mereka sebelumnya, dan menunjukkan upaya mereka untuk terlibat aktif selama aktifitas membaca. Akibatnya, kita tidak bisa menutup mata pada peran guru sebagai motivator siswa akan kebiasaan membaca yang baik dan kontributor untuk motivasi membaca siswa. Apalagi membina motivasi siswa yang merupakan bagian dari tanggung jawab guru - dalam membaca diyakini meningkatkan keterlibatan siswa.

Motivasi dikatakan memang merupakan faktor penting dalam keterlibatan siswa (Johnson \& Blair, 2003). Dengan kata lain, untuk meningkatkan keterlibatan siswa dalam membaca, para guru wajib untuk dapat memotivasi siswa dengan menciptakan instruksi pembelajaran yang menarik. Penelitian dalam motivasi membaca telah menunjukkan bahwa siswa motivasi sebenarnya dapat dirangsang oleh guru (Guthrie \& Cox, 2001; Kiemer et al., 2018). Dengan demikian, investigasi strategi guru dalam merangsang Keterlibatan siswa dalam membaca harus dipelajari lebih lanjut. 
Penelitian yang sebelumnya dilakukan menyarankan guru yang mendukung meningkatkan motivasi siswa dalam belajar yang pada gilirannya dapat menyebabkan keterlibatan membaca (Baker et al., 2000; Furtak \& Kunter, 2012; Reeve et al., 2004; Ryan \& Deci, 1985). Salah satu bentuk dukungan guru untuk motivasi siswa adalah dengan melengkapi diri mereka dengan strategi pengajaran yang efektif untuk memaksimalkan keterlibatan siswa dalam ruang kelas (Harbour et al., 2015).

Bukan berarti kita mengasumsikan bahwa guru belum melakukan yang terbaik untuk membina keterlibatan siswa dalam membaca. Bahkan, penelitian mengungkapkan hal itu guru sebenarnya terbuka untuk mengubah cara konvensional mengajar tetapi agak sulit untuk dicapai karena kurangnya waktu, sumber daya, atau bahkan penolakan siswa untuk prosedur mengajar yang tidak biasa. Negosiasi guru tentang praktik membaca EFL mereka membatasi gagasan mereka tentang praktik alternatif (Bakken \& Lund, 2018). Oleh karena itu, kerangka kerja mengajar membaca untuk jangka panjang pertunangan dipilih (Yin, 2008). Kerangka kerja ini bertujuan untuk membuat keterlibatan siswa berlangsung bahkan setelah implementasi selesai.

Berdasarkan kerangka ini, ada empat fase yang harus dilakukan dan diikuti. Fase tersebut adalah Mengamati dan Mempersonalisasi (observe and personalize), Mencari dan Mengambil (search and retrieve), Memahami dan Integrasikan (comprehend and integrate), dan Berkomunikasi dengan orang lain (communicating to others). Fase mengamati dan mempersonalisasi adalah tempat guru menyediakan kesempatan bagi siswa untuk mengamati fenomena tertentu di untuk dapat mempersonalisasikannya untuk pembelajaran mereka sendiri. Hal penting dari fase ini adalah kegiatan langsung (hands-on activity). Fase kedua adalah untuk mencari dan mengambil di mana siswa diberi kesempatan untuk mencari informasi dan mendapatkan jawaban mereka sendiri. Hal penting dari fase ini adalah bagi siswa untuk mengeksplorasi minat mereka. Fase berikutnya adalah fase memahami dan mengintegrasikan. Disinilah guru memberikan instruksi langsung tentang bacaan setelahnya memberi siswa waktu untuk membiasakan diri tentang topik tersebut dari dua fase sebelumnya. Fase terakhir adalah berkomunikasi dengan orang lain di mana siswa didorong untuk berbagi membaca di depan audiens kecil atau besar, khususnya mereka teman sekelas. Keempat fase harus dilakukan secara tertib untuk keterlibatan yang lebih lama dan lebih kuat dalam membaca.

\section{METODE PENELITIAN}

Penelitian ini mencoba untuk menyelidiki strategi guru untuk meningkatkan keterlibatan siswa dalam kegiatan pembelajaran. Oleh karena itu, penting untuk mengeksplorasi perilaku pengajaran guru dalam konteks kehidupan nyata. Untuk mencapai hal itu, Studi kasus kualitatif digunakan karena memungkinkan penelitian dikontekstualisasikan dalam lingkungan kehidupan nyata (Yin, 2008). Studi kasus dipilih sebagai desain karena dapat menjawab pertanyaan tentang manusia dan interaksi sosial (Lichtman, 2006) dan menggambarkan apa yang terjadi atau bagaimana hal-hal tersebut berlangsung (Hamied, 2017). Selain itu, pendekatan studi kasus kualitatif memberi para peneliti kesempatan untuk menganalisis berbagai detail spesifik yang sering diabaikan oleh metode lain.

Subjek penelitian adalah guru bahasa Inggris yang dipilih secara sengaja (purposive sampling). Purposive sampling dipilih karena penilaian pribadi peneliti digunakan untuk memilih sampel (Hamied, 2017). Pemilihan subjek berdasarkan pada wawancara dan rekomendasi dari kepala sekolah dan guru. Selain itu, subjek sudah memiliki pengalaman mengajar selama dua puluh tahun. Apalagi pada tahun 2011, 2013, dan 2016, ia menjadi finalis inovasi dan pembelajaran serta menjadi nomor dua di tingkat Nasional. Sampai saat ini, dia punya buku yang diterbitkan dan salah satunya adalah tentang mengajar membaca.

Data dikumpulkan dengan wawancara semi terstruktur dan dokumen analisis untuk mengumpulkan data yang memadai dan tepat tentang apa yang guru lakukan dan bagaimana dia menerapkannya. Peneliti kualitatif diharapkan untuk menggunakan lebih dari satu sumber atau setidaknya dua sumber bukti untuk 
memcari kesamaan dan pembuktian dengan menggunakan berbagai sumber dan metode pengumpulan data (Bowen, 2009). Wawancara adalah cara untuk mengumpulkan data sehubungan dengan sikap, emosi, dan pendapat orang tentang situasi di sekitar mereka (Merriam, 2009). Pertanyaan-pertanyaan dari wawancara berputar di sekitar kemungkinan bentuk strategi yang diterapkan oleh guru dalam konteks kelas. Sedangkan, analisis dokumen dilakukan untuk melihat apakah dokumen guru bertentangan atau tidak dengan wawancara. Jadi, analisis dokumen dapat menaruh kepercayaan yang lebih besar pada data dari mewawancarai atau membuat kontradiksi.

Wawancara semi-terstruktur dilakukan sekitar 35 menit untuk menemukan lebih banyak informasi mendalam tentang strategi guru bahasa Inggris dalam menghadapi penurunan minat membaca siswa dan bagaimana meningkatkan keterlibatan mereka dalam bacaan. Wawancara tersebut dilakukan dalam Bahasa Indonesia. Dengan izin dari subjeknya, wawancara direkam dengan audio-recorder. Setelah itu, rekaman audio wawancara ditranskrip secara verbatim dan kemudian diterjemahkan ke dalam bahasa Inggris. Subjek terkadang menjawab pertanyaan dengan cara alih kode (Bahasa Indonesia dan Inggris). Dengan demikian, peneliti menyimpan komentar subjek penelitian demi orisinalitas data. Selain itu, analisis dokumen dilakukan dengan menganalisis rencana pelaksanaan pembelajaran (RPP). Karena peneliti mencari strategi yang digunakan oleh guru, oleh karena itu analisisnya terutama dilakukan pada kegiatan pembelajaran di dalam RPP.

\section{HASIL DAN PEMBAHASAN}

Seperti disebutkan di bagian pendahuluan, strategi guru untuk memaksimalkan keterlibatan siswa dalam membaca mengikuti empat fase kerangka kerja (Guthrie \& Cox, 2001). Jadi, untuk menemukan strategi subjek selama setiap fase pengajaran berdasarkan kerangka kerja keterlibatan membaca, hasil dan pembahasan akan disajikan dalam empat bagian juga.

\subsection{Hasil}

\section{Mengamati dan Mempersonalisasi}

Subjek sangat percaya bahwa aktifitas membaca di dalam kelas harus dilakukan dalam tahap demi tahap. Dia menyarankan agar para siswa diajarkan sesuatu yang mudah terlebih dahulu sebelum naik ke level sedang dan terakhir ke yang lebih sulit. Dia menegaskan - berkalikali dengan kata-kata yang berbeda - bahwa siswa sekolah menengah sedang berjuang belajar kemampuan bahasa Inggris secara umum, termasuk kemampuan membaca. Dia juga mengakui fakta bahwa siswa memiliki latar belakang pengetahuan dan tingkat pemahaman. Apalagi menurutnya, tidak adanya Bahasa Inggris sebagai mata pelajaran yang akan diajarkan di sekolah dasar semakin memperumit masalah. Dengan demikian, ketika siswa masuk sekolah menengah, bahasa Inggris mereka masih sangat dasar. Dia menyatakan:

\section{Excerpt 1}

"Sekarang berbeda dari masa lalu. Di masa lalu, sekolah dasar memiliki konten lokal (bahasa Inggris), sekarang tidak. Secara otomatis, kemampuan siswa juga diturunkan. Jadi itu seperti mengajar siswa sekolah dasar di sekolah menengah lagi."

Dengan mengingat hal itu, subjek berargumen kuat bahwa belajar membaca tidak boleh terburu-buru. Perlu bagi siswa untuk mengamati pembelajaran terlebih dahulu. Dia menambahkan bahwa brainstorming dalam bentuk pertanyaan juga diperlukan untuk mengetahui pemahaman siswa tentang topik yang akan dibahas. Karena itu, sebagai alat untuk observasi, dia akan membawa realia, gambar, dan juga video sebagai kegiatan awal sebelum membaca. Sejalan dengan wawancara, kegiatan langsung seperti ini (melihat, menyentuh, mengalami) juga sesuai dengan rencana pelaksanaan pembelajaran.

Setelah memberi siswa waktu untuk membiasakan diri dengan brainstorming dan kegiatan langsung (hands-on activity), subjek menyatakan bahwa dia akan membimbing siswa-siswanya untuk menulis pertanyaan dengan memberi mereka template untuk diselesaikan. Dia menyebut ini sebagai bagian dari Pengajaran Kuantum (Quantum Teaching). Subjek membenarkan bahwa dia menggunakan pengajaran kuantum karena dia menemukan bahwa pemahaman siswa tentang teks masih rendah. Karena itu, ia memberikan template 
untuk para siswa. Template pada dasarnya adalah serangkaian pertanyaan tidak lengkap yang diatur sebelumnya oleh guru untuk dikembangkan dan dilengkapi oleh siswa. Siswa diminta untuk melengkapi template dengan pribadi mereka aktivitas harian yang pada akhirnya menghasilkan versi yang dipersonalisasi dari kegiatan setiap siswa. Namun demikian, subjek mengakui bahwa menggunakan template memiliki kekuatan dan kelemahan sendiri juga. Excerpt 2

“... Keuntungannya adalah bahwa pemikiran analitis siswa berfungsi. Tetapi sebagian besar terjadi pada siswa dengan HOTS (Higher Order Thinking Ketrampilan). Untuk siswa dengan LOTS (Keterampilan Berpikir Tingkat Bawah), the analisis masih lemah"

Untuk siswa dengan level yang lebih tinggi kemahiran, template dapat membantu dalam mengaktifkan analisis mereka. Sebaliknya, siswa dengan tingkat kemahiran yang lebih rendah masih menemukan kesulitann bahkan dengan bantuan template dari guru. Terlepas dari masalah yang disebutkan di atas, dia percaya itu seiring berjalannya waktu, perubahan positif akan terlihat dari siswa.

\section{Mencari dan Mengambil}

Dalam wawancara, subjek merefleksikan salah satu strategi dia telah menerapkan praktik mengajar di masa lalu yang disebut "Lingkaran sastra" yang karenanya tidak dapat ditemukan dalam rencana pelaksanaan pemlajaran saat ini. Di lingkaran sastra, siswa disediakan dengan 40 buku dari Cambridge reader dengan level kesulitan berbeda; pemula ke menengah.

\section{Excerpt 3}

"Anak-anak yang cukup berani untuk mengambil buku level 3 (menengah) - yang lebih tebal - biasanya sudah memiliki pengetahuan sebelumnya dan mereka senang membaca sejak sekolah dasar. Mereka juga difasilitasi dengan baik oleh orang tua mereka. Sementara itu, anak-anak lain memilih buku pemula karena mereka takut jika mereka tidak mengerti (buku yang lebih tebal)."

Subjek menyatakan bahwa siswa bebas memilih buku berdasarkan pada minat mereka sendiri. Akibatnya, subjek setiap siswa cenderung mencari buku berdasarkan persepsi mereka tentang kemampuan berbahasa Inggris mereka sendiri.

\section{Memahami dan Mengintegrasikan}

Subjek berbicara dengan penuh semangat tentang mengajar dan belajar. Jadi, agak mengejutkan mengetahui bahwa pada awalnya ia tidak menyukai pekerjaannya sebagai seorang guru. Dia mengatakan bahwa lima tahun pertama pengajarannya berantakan. Namun, dia menyatakan bahwa semangat para siswa adalah panggilan. Setelah itu, dia mulai membaca buku tentang metode pengajaran dan media pengajaran. Ini membantunya masuk menemukan lebih banyak strategi untuk diajarkan di kelas. Strateginya ditemukan dari kesenangan barunya untuk membaca diharapkan untuk membuat siswa memahami bacaan dengan lebih baik dan kemudian diintegrasikan menjadi pembelajaran mereka sendiri. Para siswa harus dilengkapi dengan strategi agar mampu menemukan jawaban mereka sendiri dan memberdayakan diri mereka sendiri untuk mengelola pembelajaran mereka sendiri (Griffiths, 2007). Di di sisi lain, subjek menambahkan bahwa kadang-kadang ide untuk strategi mengajar datang secara alami bahkan tanpa merencanakannya terlebih dahulu.

Excerpt 4

"Gagasan terkadang berkembang ketika kita berada di depan siswa tetapi ketika membuat rencana untuk mengajar sebelum kelas, itu adalah hal biasa. Namun, jika saya di depan para siswa saya tiba-tiba berpikir 'Saya pikir strategis ini akan baik untuk ditambahkan."

Selain itu, subjek juga melakukan bimbingan pribadi dengan siswa untuk memantau kemajuan dan pemahaman mereka bacaan dibahas.

\section{Berkomunikasi dengan Orang Lain}

Subjek menyebutkan bahwa ada dua siswa di kelas yang menonjol dari teman-teman sekelas mereka. Karena itu, dia sering meminta mereka untuk mengajari teman-teman mereka. Namun, para siswa masih enggan melakukan bimbingan belajar. Dia mengutip kata-kata mereka ketika diminta untuk membantu teman mereka, 'ah Ibu, jangan saya!' Meskipun mereka tidak benar-benar ingin bekerja sama, subjek 
menyatakan bahwa dia akan mendesak mereka untuk membantu siswa lainnya. Karena dia percaya bahwa berbicara di antara diri mereka sendiri (para siswa) tidak mengintimidasi daripada berbicara dengan guru.

\subsection{Pembahasan}

\section{Mengamati dan Personalisasi}

Subjek mengatakan bahwa ia memulai pelajaran secara bertahap dengan brainstorming dan kegiatan langsung (hands-on activity). Kegiatan langsung dalam fase observasi dan personalisasi akan memberikan lebih banyak kesempatan bagi siswa untuk melihat, menyentuh, dan mengalami pembelajaran sebelum mempersonalisasikannya untuk mereka sendiri belajar (Guthrie \& Cox, 2001). Sama dengan pernyataan ini, ditegaskan bahwa anakanak belajar lebih baik dari kegiatan langsung yang memungkinkan mereka untuk mencerna pengalaman abstrak dan virtual dengan cara yang diduga lebih mudah (Musthafa, 2010). Bahkan, tidak hanya anak-anak tetapi juga siswa dari segala usia dapat mengambil manfaat dari kegiatan langsung. Ini menunjukkan bahwa Subjek lebih menghargai proses belajar daripada hanya mentransfer pengetahuan kepada siswa. Dia sadar memiliki itu landasan yang baik pada topik yang dipelajari sangat penting sebelumnya pindah ke konsep yang lebih sulit.

Mengenai pengajaran kuantum (Quantum teaching) yang dilakukan guru, juga didukung oleh sebuah penelitian berjudul "Upaya Meningkatkan Pembelajaran Siswa melalui Penerapan Model Pengajaran Pembelajaran Quantum". Penelitian tersebut menemukan bahwa Quantum Teaching membuat siswa menjadi lebih aktif dalam mengekspresikan pendapat, berdiskusi lebih hidup, dan menjadi lebih energik dalam melakukan tugas yang diberikan(Yanuarti\&Sobandi, 2016). Pengajaran kuantum juga dikatakan memungkinkan guru untuk mengetahuinya kemungkinan strategi yang dibutuhkan oleh siswa.

\section{Mencari dan Mengambil}

Dengan memilih buku sesuai minat mereka, siswa lebih termotivasi untuk membaca. Memberikan kesempatan kepada anak-anak untuk memilih mereka memiliki buku untuk dibaca membantu mendorong keterlibatan dalam tugas (Kiefer, 2015). Terlebih lagi, alih- alih merasa frustrasi, mereka dapat mengalami kesuksesan (Daniels, 2006). Ketika lingkaran sastra berlanjut, subjek berpendapat bahwa siswa yang awalnya memilih buku tingkat pemula secara bertahap menikmati membaca buku dan mulai tertarik pada buku dengan tingkat kesulitan yang lebih tinggi.

Lingkaran sastra penting dan dapat diadaptasi karena membantu anak-anak menyukai buku yang telah mereka pilih dan menjadi lebih terlibat karena mereka terlibat dalam keputusan (Daniels, 2006). Tambahan, dalam rencana pelajarannya, subjek mendorong siswa untuk mencari bahan dari sumber lain di luar kelas yang berkaitan dengan topik yang dibahas. Namun, efektivitas strategi ini tidak dapat dipastikan jika siswa tidak memiliki motivasi diri atau ada tidak ada tekanan eksternal dari guru.

\section{Memahami dan Mengintegrasi}

Pengajaran Kuantum dalam bentuk komunikasi satu per satu dengan siswa yang disebut sebelumnya juga merupakan bagian dari fase mengamati dan mempersonalisasi. Subjek mengakui bahwa berbicara dengan siswa satu per satu sangat menyita waktu. Namun, penting untuk melakukan hal tersebut untuk memeriksa pemahaman siswa dan untuk melihat siswa mana yang paling membutuhkan bantuan. Dengan cara itu, dia percaya bahwa dia dapat mengakomodasi semuanya muridmuridnya di kelas.

Penelitian lain menemukan bahwa bekerja pada level satu-per-satu dengan siswa adalah bagian dari keterlibatan guru untuk mengatasi masalah perilaku atau masalah akademik siswa (Orlich et al., 2009). Meskipun memakan waktu, satu lawan satu bimbingan bisa menjadi alat yang ampuh untuk subjek secara tepat memantau setiap kekuatan dan kelemahan siswanya selama bacaan. Dengan melakukan itu, dia juga dapat melibatkan siswa secara nyata dalam diskusi tentang bacaan.

\section{Berkomunikasi dengan Orang Lain}

Guru menyatakan bahwa keterlibatan siswa dalam membaca dapat ditingkatkan dengan bimbingan teman sebaya (peer-tutoring). Di sisi lain, studi menyatakan bahwa salah satu persyaratan peer-tutoring untuk menjadi sukses adalah para calon tutor mengikuti panduan tutor 
selama setidaknya satu minggu (De Backer et al., 2015). Guru harus membimbing siswa yang dipilih menjadi tutor yang baik terlebih dahulu sebelum menugaskan mereka untuk mengajari teman-teman mereka. Jadi, mungkin guru harus memikirkan kembali sebelum menugaskan siswa untuk mengajari teman-teman mereka secara langsung, apalagi jika para siswa menunjukkan keengganan untuk melakukannya. Mungkin itu adalah strategi subjek agar siswa yang berprestasi tersebut memaksimalkan waktu senggang mereka karena menyelesaikan pekerjaan mereka lebih cepat daripada rekanrekan mereka. Atau bisa saja guru menganggap siswa tersebut cukup mampu untuk melakukan bimbingan belajar kepada teman mereka.

Satu penelitian berjudul "Teacher and peer support for young adolescents' motivation, engagement, and school belonging" menegaskan bahwa dukungan guru dan teman sebaya dapat menumbuhkan lingkungan pembelajaran yang responsif karena kedua aspek memiliki sifat akademik dan sosial (Kiefer, 2015). Selain itu, dukungan teman sebaya dan guru memiliki implikasi unik untuk mendukung tidak hanya keterlibatan di ruang kelas tetapi juga motivasi akademik dan sekolah. Subjek juga mendorong siswa untuk bekerja dalam kelompok kecil dan mendiskusikan apa yang mereka baca. Ini adalah semacam pembelajaran kolaboratif di dimana siswa diminta untuk membagikan apa yang telah mereka baca dengan teman yang minat bukunya yang sama dan kemudian memberikan ulasan singkat berdasarkan diskusi itu.

\section{KESIMPULAN}

Penelitian ini telah mengeksplorasi strategi yang digunakan oleh guru yang dianggap berhasil dalam melibatkan siswa dalam aktifitas membaca. Berdasarkan strategi untuk keterlibatan jangka panjang oleh (Guthrie \& Cox, 2001), guru harus memenuhi setiap fase untuk melibatkan siswa bacaan. Untungnya, semua strategi tersebut disebutkan oleh guru ditegaskan untuk melibatkan siswa dalam membaca. Strateginya yang direkomendasikan oleh guru adalah kegiatan langsung, lingkaran sastra, pengajaran kuantum, pembelajaran kolaboratif, dan bimbingan teman sebaya. Setiap strategi divalidasi secara empiris oleh penelitian lain untuk dapat mempromosikan keterlibatan siswa dalam aktifitas membaca. Namun, modifikasi dan pertimbangan harus dipikirkan sebelumnya menerapkan strategi di kelas. Di sisi lain, strategi alternatif untuk keterlibatan membaca telah disarankan oleh guru. Untuk penelitian selanjutnya, itu direkomendasikan untuk melibatkan lebih banyak guru yang unggul dalam penelitian ini. Selain itu, melibatkan guru yang lain juga bisa bermanfaat dengan tujuan peningkatan kualitas mengajar guru. Pengamatan selama dan setelah penelitian juga harus dilakukan untuk pastikan setiap strategi bekerja untuk jangka panjang atau tidak.

\section{DAFTAR RUJUKAN}

Baker, L., Afflerbach, P., \& Reinking, D. (1996). Developing engaged readers in school and home communities (first). L. Erlbaum Associates.

Baker, L., Dreher, M. J., \& Guthrie, J. T. (2000). Engaging young readers : promoting achievement and motivation. Guilford Press.

Bakken, A. S., \& Lund, R. E. (2018). Why should learners of English read? Norwegian English teachers' notions of EFL reading. Teaching and Teacher Education, 70(1), 78-87. https://doi.org/10.1016/j.tate.2017.11.002

Bowen, G. A. (2009). Document analysis as a qualitative research method. Qualitative Research Journal, 9(2), 27-40. https://doi.org/10.3316/QRJ0902027

Daniels, H. (2006). What's the Next Big Thing with Literature Circles? Voices from the Middle, 13(4), 10-16. http://www.homeedsa.com/

De Backer, L., Van Keer, H., \& Valcke, M. (2015). Promoting university students' metacognitive regulation through peer learning: the potential of reciprocal peer tutoring. Higher Education, 70(3), 469-486. https:// doi.org/10.1007/s10734-014-9849-3

Downer, J. T., Rimm-Kaufman, S. E., \& Pianta, R. C. (2007). How do classroom conditions and children's risk for school problems contribute to children's behavioral engagement in learning? School Psychology Review, 36(3), 413-432. https://psycnet.apa.org/record/2007-15262-006

Fredricks, J. A., Blumenfeld, P. C., \& Paris, A. H. (2004). School Engagement: Potential of the Concept, State of the 
Evidence. Review of Educational Research, 74(1), 59-109. https://doi.org/10.3102/00346543074001059

Furtak, E. M., \& Kunter, M. (2012). Effects of autonomy-supportive teaching on student learning and motivation. Journal of Experimental Education, 80(3), 284-316. https://doi.org/10.1080/00220973.2011.573019

Griffiths, C. (2007). Language learning strategies: students' and teachers' perceptions. ELT Journal, 61(2), 91-99. https://doi.org/10.1093/elt/ccm001

Guthrie, J. T., \& Cox, K. E. (2001). Classroom Conditions for Motivation and Engagement in Reading. Educational Psychology Review, 13(3), 283-302. https://doi.org/10.1023/A:1016627907001

Guthrie, J. T., \& Wigfield, A. (2000). Engagement and motivation in reading. In Handbook of reading research (Pearson, R. Barr, Vol. 3, pp. 403-422). Lawrence Erlbaum Associates Publishers. https://psycnet.apa.org/ record/2000-07600-009

Hamied, F. A. (2017). Research Methods: A Guide For First-Time Researchers. UPI PRESS.

Harbour, K. E., Evanovich, L. L., Sweigart, C. A., \& Hughes, L. E. (2015). A brief review of effective teaching practices that maximize student engagement. Preventing School Failure, 59(1), 5-13. https://doi.org/10.1 080/1045988X.2014.919136

Johnson, D., \& Blair, A. (2003). The Importance and Use of Student Self-Selected Literature to Reading Engagement in an Elementary Reading Curriculum. Reading Horizons: A Journal of Literacy and Language Arts, 43(3). https://scholarworks.wmich.edu/reading_horizons/vol43/iss3/3

Kiefer, S. M. |Alley. K. M. |Ellerbrock. C. R. (2015). Teacher and Peer Support for Young Adolescents' Motivation, Engagement, and School Belonging. RMLE Online: Research in Middle Level Education, 38(8).

Kiemer, K., Gröschner, A., Kunter, M., \& Seidel, T. (2018). Instructional and motivational classroom discourse and their relationship with teacher autonomy and competence support-findings from teacher professional development. European Journal of Psychology of Education, 33(2), 377-402. https://doi.org/10.1007/ s10212-016-0324-7

Lichtman, M. (2006). Qualitative research in education : a user's guide. Sage Publications.

Mahatmya, D., Lohman, B. J., Matjasko, J. L., \& Farb, A. F. (2012). Engagement across developmental periods. In Handbook of Research on Student Engagement (pp. 45-63). Springer US. https://doi.org/10.1007/9781-4614-2018-7_3

Merriam, S. B. (2009). Qualitative Research: A Guide to Design and Implementation (Third). Jossey-Bass.

Musthafa, B. (2010). Teaching English to Young Learners in Indonesia: Essential Requirements. Educationts, 4(2), $120-126$.

Orlich, D. C., Harder, R. J., Callahan, R. C., Trevisan, M. S., \& Brown, A. H. (2009). Teaching Strategies: A Guide to Effective Instruction. Cengage Learning.

Philp, J., \& Duchesne, S. (2016). Exploring Engagement in Tasks in the Language Classroom. Annual Review of Applied Linguistics, 36, 50-72. https://doi.org/10.1017/S0267190515000094

Reeve, J., Jang, H., Carrell, D., Jeon, S., \& Barch, J. (2004). Enhancing students' engagement by increasing teachers' autonomy support. Motivation and Emotion, 28(2), 147-169. https://doi.org/10.1023/ B:MOEM.0000032312.95499.6f

Ryan, R. M., \& Deci, E. L. (1985). Self-Determination Theory and the Facilitation of Intrinsic Motivation, Social Development, and Well-Being Self-Determination Theory. The American Psychological Association, 55(1), 68-78.

Skinner, E. A., \& Belmont, M. J. (1993). Motivation in the Classroom: Reciprocal Effects of Teacher Behavior and Student Engagement Across the School Year. Journal of Educational Psychology, 85(4), 571-581. https:// doi.org/10.1037/0022-0663.85.4.571

Skinner, E. A., Wellborn, J. G., \& Connell, J. P. (1990). What It Takes to Do Well in School and Whether I've Got It: A Process Model of Perceived Control and Children's Engagement and Achievement in School. Journal of Educational Psychology, 82(1), 22-32. https://doi.org/10.1037/0022-0663.82.1.22

Yanuarti, A., \& Sobandi, A. (2016). UPAYA MENINGKATKAN HASIL BELAJAR SISWA MELALUI PENERAPAN MODEL PEMBELAJARAN QUANTUM TEACHING. Jurnal Pendidikan Manajemen Perkantoran, 1(1), 18. https://doi.org/10.17509/jpm.v1i1.3261

Yin, R. K. (2008). Case Study Research Design and Methods (Fourth). Sage Publications. 